\title{
Evaluating The Importance Of Competencies Within Accounting Information Systems Curricula
}

Richard B. Dull, (Email: rdull@clemson.edu), Clemson University Sally A. Webber, (Email: swebber@niu.edu), Northern Illinois University Barbara Apostolou, (Email: acapos@1su.edu), Louisiana State University John M. Hassell, (Email: jhassell@iupui.edu), Indiana University

\begin{abstract}
In International Education Guideline No. 11, the International Federation of Accountants identified the essential information technology (IT) competencies, knowledge, and skills required for entry-level accounting positions. These IT competencies are classified into three categories: (1) IT concepts for business systems (nine competencies), (2) internal control in computer-based business systems (six competencies), and (3) the roles of the professional accountant in information systems (18 competencies classified into three subcategories). In this exploratory study, we surveyed accounting information systems educators about the relative importance of the IFAC competencies to prepare undergraduate students for entry-level accounting positions. The results provide accounting educators with an understanding of current practice regarding the relative emphasis placed on IT competencies in AIS courses. Using this information, the results may be used to guide the allocation of resources within the AIS curriculum.
\end{abstract}

\section{INTRODUCTION}

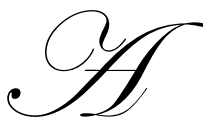

ccounting information systems, compared to traditional accounting topics, is a relatively young discipline. This youth, combined with the rise of technology expectations for today's accounting graduates, provides diversity in topic coverage among educational institutions. The trend at many colleges and universities is to include more technology within accounting courses and more courses about technology within the general curriculum. Even with an increase in technical coverage, anecdotal evidence suggests a wide disparity exists in the coverage of the information technology (IT) competencies across accounting programs. Several studies over the last decade have documented a wide variation of IT concepts and topics covered in the basic accounting information systems (AIS) course (Bain, Blankley \& Smith 2002, Macur 1998, Walton 1997, Groomer \& Murthy 1996, Borthick 1996, Smith \& Bain 1993). Additionally, large differences in IT coverage exist in textbooks for financial and managerial accounting, tax, and auditing courses.

To provide guidance on what IT competencies accountants should have when entering the workforce, professional advisory bodies have identified a set of IT competencies that should be covered in business school curricula. The International Federation of Accountants (IFAC) in its International Education Guideline No. 11 (1995, revised 1998) entitled "Information Technology in the Accounting Curriculum," listed these competencies. An AICPA (1996) task force endorsed the competencies identified by the IFAC. Thus, the IFAC and AICPA indicate that by including the IT competencies in the accounting curriculum, accounting graduates will possess an appropriate baseline of technical knowledge.

Our primary interest in conducting the study is how AIS faculty members rate the importance of the IT competencies in the International Education Guideline No. 11 (1995). 
Within the IT Concepts area, the study found that the respondents believe that less technical issues (data organization, management use of information and transaction processing) are more important than more technical issues (hardware, system software, and application software). Within the internal control area of the framework, the study found preferences for risk assessment and control activities over the concepts of the control framework and monitoring of control compliance.

The findings may provide guidance to several groups of readers. New AIS faculty may use this study to evaluate content for their courses, providing them the perspective of current faculty. Readers may also use the results to evaluate the cumulative importance of the concepts relative to their own programs. The findings may also be used to promote discussions among accounting faculty members related to potential curriculum changes. This study can be used as a tool to evaluate where a specific program differs from concepts and topics believed to be important by other AIS educators, within the context of Guideline No. 11. For example, a school that focuses on technical issues, such as hardware and software, can see where it stands relative to other institutions; the authors are not suggesting conformity is desired, but knowing how a program is positioned can help in decision-making and marketing efforts.

The remainder of the paper is structured as follows. The first section includes a brief review of related AIS education literature. The second section describes our research design. Sections three and four present the results and related discussion.

\section{LITERATURE REVIEW}

Unlike many traditional accounting courses, the content of AIS courses typically varies widely across accounting programs. Part of this variation is due to the lack of "generally accepted" guidelines for technology in accounting curricula. Many schools relegate the teaching of IT to one or two classes. Typically, a first course may consist of "tools" such as spreadsheets and databases, which are often taught in computer science or information systems departments by non-accounting faculty. The second course is generally an AIS course, taught by accounting faculty. It has been suggested that the background of the instructor affects course content (Groomer \& Murthy, 1996), which can lead to variation in AIS content among schools and across instructors within programs.

Previous research has documented the diversity in information systems courses provided to, and required of, accounting graduates. Walton (1997) surveyed undergraduate accounting programs and reported that nearly all accounting majors receive some exposure to IS concepts, mostly in the form of a required computer information systems (CIS) course or an AIS course. Walton found that over $97 \%$ of her sample schools required students to take some IS-related course(s). Additionally, Walton reported that $24 \%$ of respondents required management information systems (MIS) ${ }^{1}$ but not AIS courses. She also found that while $67 \%$ of schools offered an AIS course, only one-half of her responding schools required an AIS course for accounting majors. Walton's results demonstrate the wide diversity of IT requirements among schools.

The current study looks at course content from the perspective of how the content fits into the expectations of employers (via the standards produced by their professional organizations.)

While technology exposure appears to be the norm in accounting curricula, a wide gap exists between exposure to IT competencies and the detailed expectations of entry-level accountants enumerated in Guideline No. 11, which describes certain IT knowledge and skills that are required as part of an accountant's prequalification education. Additionally, other skills are enumerated for postqualification education for specialists. Our study focuses on the prequalification education because of the direct applicability to the education of students entering the accounting profession.

Figure 1 describes the categories considered in this study. The first category is IT Concepts for Business Systems; the second is Internal Controls in Computer Based Systems. The third category, Roles of Professional Accountants in IS, is considered in a second study, with the category descriptions presented in Figure 2. Guideline No. 11 specifies four roles that accountants should be prepared to assume with respect to information systems: (1) user, (2) manager, (3) designer and (4) evaluator. Every accountant is expected to be a user. Additionally, each 
accountant is expected to assume at least one of the other roles. The second study looks at preferences for the "nonuser" roles. Guideline No. 11 argues that in today's technological environment, IT competency is required for virtually all accounting professionals.

Previous AIS research regarding curriculum issues has used the IFAC guidelines. Macur (1998) used the IFAC guidelines to categorize syllabi of surveyed institutions to describe current AIS course content. Callaghan, Peacock \& Savage (2000) compared their institution's accounting curriculum, including the content of three AIS courses, to the IFAC guidelines. Based on their comparison, the authors identified weaknesses in their program and developed a course to address those weaknesses. In a second study, Callaghan, Peacock \& Savage (2001) surveyed business professionals from a variety of industries regarding the "user" role (described in the IFAC guidelines) and IT skills taught in the framework of an accounting curriculum. The study did not prioritize the roles per se, but listed each item in Guideline No. 11 and asked if it should or should not be included in the accounting curriculum at the researchers' institution. If included, the participants were asked their opinion as to what extent the item should be included. That study found that technical and programming topics were least desired by practitioners, while traditional accounting and high level systems topics were highly rated. Our study adds to the previous IFAC based research by measuring the relative importance of IT competencies to academics - those preparing future entrants to the job market.

In addition to the diversity of course offerings/requirements, research has addressed what should be taught in AIS courses. We highlight only a few of these studies because the body of work contains similar characteristics. Smith \& Bain (1993) analyzed the contents of major AIS textbooks and surveyed AIS instructors regarding the 22 major sections identified from their textbook analysis, plus two additional topics that were not identified in their analysis. They found that some topics with perceived importance to faculty received relatively low textbook coverage.

Bain, Blankley \& Smith (2002), surveyed professionals and faculty, and reported the rankings each provided for several identified topics. Their focus is on the first AIS course, while the current study evaluates topics for the entire AIS curriculum. Another significant difference to their approach, and the current study, is that the current study uses topics provided by the profession as a whole (through IFAC/AICPA publications), rather than topics identified by textbook authors.

Authors of previous research, in addition to surveying experienced faculty, have developed questionnaires and surveyed practitioners (Heagy \& McMickle 1988), recent graduates (Davis \& Leitch 1988), and departmental chairpersons (Groomer \& Murthy 1996). Heagy \& McMickle (1988) found differences in what faculty and practitioners thought important and prioritized a list of topics in order of importance by both groups. Similarly, Davis \& Leitch (1988) made curriculum suggestions based on their findings. They suggested topics for the "first" AIS course, as well as other undergraduate and graduate AIS courses.

Using a self-developed list of content items as well as collecting detailed demographics, Groomer \& Murthy (1996) suggest that the diversity of AIS courses may be due to, among other things, the lack of authoritative guidance for the topics covered.

A major difference between the previous studies and ours is that we focus on IT competencies identified by the profession for which we prepare our students, as described in the IFAC document, not those competencies identified in texts or other academic literature. We do not assert that texts and academic literature are less important, but simply that the profession's stated needs should be considered.

In an early study of course content, Davis \& Leitch (1988), surveyed recent graduates and AIS faculty regarding sixty topics the researchers deemed important. They then recommended the content for undergraduate and masters program AIS courses. Again, as with previous studies, suggested topical coverage overlaps with those in Guideline No. 11, but the specific topics differ. Our research extends prior research by considering competencies presented in Guideline No. 11 and endorsed by the accounting profession, rather than measuring topics identified and 
deemed important by the individual researchers. We add to the extant literature by using specific topics and structure based on what the accounting profession indicates should be included in accounting curricula.

\section{RESEARCH DESIGN}

The research consisted of two separate but related studies. In Study 1, accounting educators with AIS responsibilities rated the relative importance of IT Concepts competencies and of Internal Control competencies. Due to time constraints, based on the length of the instruments, the level four factors for the roles were not examined. In order to provide some information on the individual competencies among the roles, a second study was initiated.

In Study 2, the instruments were mailed to a small group of accounting educators that the authors considered to be leaders ${ }^{2}$ in AIS accounting education to assess the relative importance of IT competencies related to the Roles of Accountants. In both studies, relative importance was assessed using the Analytic Hierarchy Process (AHP).

\section{THE ANALYTIC HIERARCHY PROCESS (AHP)}

Developed by Thomas Saaty, (Saaty 1986, 1988, 1994), the AHP is a mathematical tool used to measure complex subjective judgments. It is useful when qualitative criteria, such as IT competencies, are used in decisionmaking, and it is especially appropriate when decision factors tend to have a hierarchical structure. AHP analysis consists of four principal stages. In the first stage, a hierarchy is constructed of the factors relevant to a particular decision. . The second stage requires that subjects make all possible paired comparisons between factors within the hierarchy. Each comparison consists of choosing the most important item in a pair and then quantifying the magnitude of its importance in the pair using a nine-point intensity scale. In the scale, the value of one indicates that items in the pair are equally important, while the value of nine is extreme importance. In stage three, the pairwise ratings are synthesized to produce a priority weight for each factor. The synthesis also produces an inconsistency ratio (IR), which measures how inconsistent or coherent the comparisons were. An IR of 10 or less is considered to be reasonable. The fourth stage of AHP analysis is to aggregate models for an overall impression of the subject pool's judgments. Expert Choice Team EC software (1998) was used for the analysis. Apostolou \& Hassell (1993) review AHP accounting research.

\section{HIERARCHY OF IT COMPETENCIES}

Guideline No. 11 groups IT competencies into categories, which are presented in Figure 1. Level 1 is the goal of the subject's judgment and of this research: namely, to assess the relative importance of the IT competencies identified in IFAC Guideline No. 11. Level 2 reflects the three IT competency categories: (1) IT concepts for business systems, (2) internal control in computer-based business systems, and (3) roles of the professional accountant in information systems. Finally, Level 3 specifies the individual IT competencies within the respective parent category. 


\section{Figure 1}

Study 1: Information Technology Competencies for Entry-Level Accounting Professionals

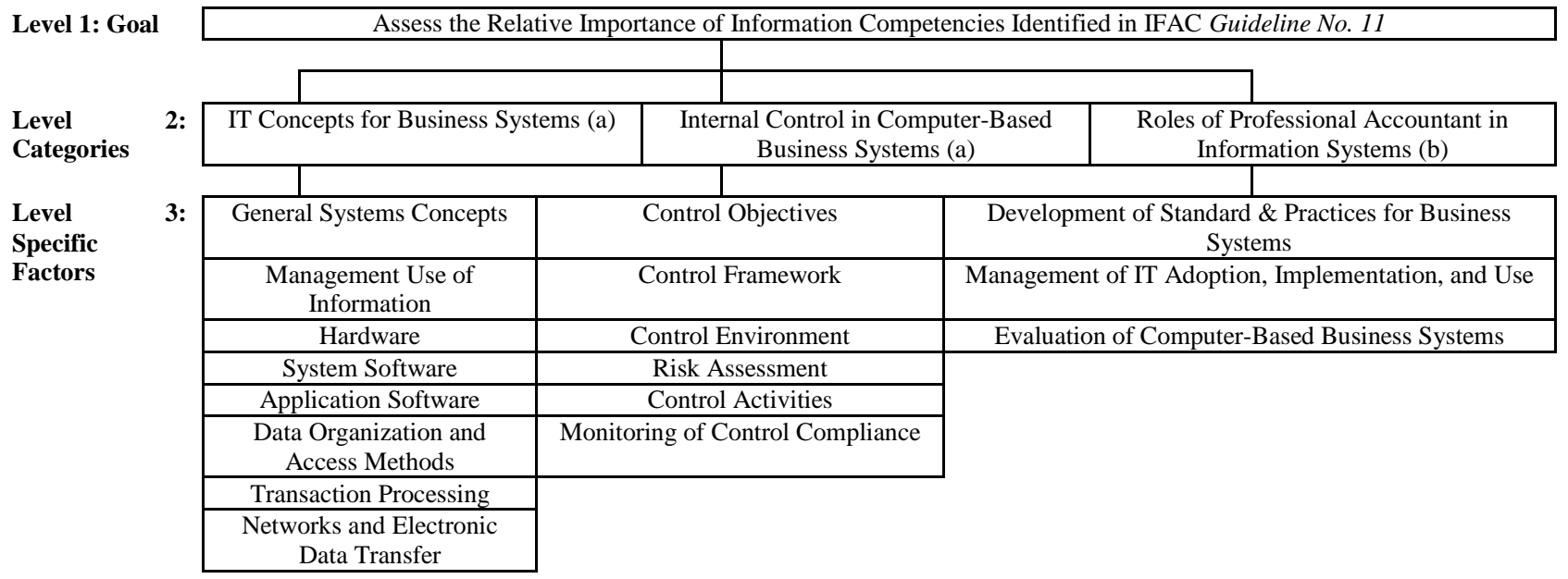

Source: International Federation of Accountants, International Education Guideline No. 11 (1995, revised 1998)

(a) Abbreviated descriptions. See Figure 1, Concluded for more complete definitions of the concepts.

(b) Considered in Study 2.

IT Concepts For Business Systems

General systems concepts (GSC) Nature and types of systems; system architectures; control \& feedback in systems; nature \& types of information; information attributes; role of information within a business.

Management use of information (MUI) Decision theory; human information processing; typical transaction processing; communication of information; financial analysis.

Hardware(H) Components of a computer configuration; processing units; I/O devices; physical storage devices; communication devices.

System software (SS) Software configuration; operating systems; communications systems; security software; utility software; programming languages/compilers; programming aids \& interactive programming software; library management systems; data management systems.

Application software (AS) Application software strategy (i.e., piecemeal v. enterprise; package v. custom; distributed v. centralized; end-user computing).

Data organization and access methods (DOAM) Data structures and file organization; access methods \& file maintenance; types of data files; data base management systems; document management.

Transaction processing (TP) General application processing phases (data entry, edit, master file updates, queries, audit trail, etc.); processing modes (batch, on-line, etc.); revenue and purchases cycles documents \& records.

Networks and electronic data transfer (NEDT) Network components configurations \& designs; data communication \& transmission devices/software; message \& document communication (EDI, POS, EFTS, etc.); operations management \& control.

Internal Control In Computer-Based Business Systems

Control objectives (CO) Risks \& exposures in computer-based information systems; effect of computer on processing controls; effect of IT on organization \& controls; responsibility for control; effectiveness \& efficiency of operations; reliability of financial reporting; compliance with applicable laws \& regulations; cost effectiveness of control procedures.

Control framework (CF)

Control environment (CE) Management philosophy \& operating style; plan/structure of organization; methods to communicate the assignment of authority \& responsibility; management control methods; systems development methodology; controls over system implementation; control over system \& program changes; personnel management methods; external controls.

Risk assessment (RA) Risk exposures; probability of loss; consequences; preventive/detective/corrective strategies.

Control activities (CA) Accounting system; control procedures; control design; control over data integrity, privacy \& security; continuity of processing/disaster recovery planning \& control; IS processing/operations.

Monitoring of control compliance (MCC) Roles of management users, internal auditors, and external auditors. 
Figure 2

Study 2: Information Technology Competencies for Entry-Level Accounting Professionals Related to Roles of Professional Accountants in Information Systems

\begin{tabular}{|c|c|c|c|}
\hline Level 1: Goal & \multicolumn{3}{|c|}{$\begin{array}{l}\text { Assess the Relative Importance of Roles of Professional Accountant in Information Systems Identified in IFAC Guideline No. } \\
11\end{array}$} \\
\hline $\begin{array}{l}\text { Level } \\
\text { Categories }\end{array}$ & $\begin{array}{l}\text { Development of Standards \& Practices } \\
\text { for Business Systems (a) }\end{array}$ & $\begin{array}{l}\text { Management of IT Adoption, } \\
\text { Implementation, and Use (a) }\end{array}$ & $\begin{array}{c}\text { Evaluation of Computer-Based } \\
\text { Business Systems (a) }\end{array}$ \\
\hline \multirow[t]{9}{*}{$\begin{array}{l}\text { Level 3: Specific } \\
\text { Factors }\end{array}$} & $\begin{array}{l}\text { Role of Information in Organization } \\
\text { Design \& Behavior }\end{array}$ & Strategic Considerations in IT Development & $\begin{array}{l}\text { Legal, Ethical, Auditing, and IS } \\
\text { Control Standards }\end{array}$ \\
\hline & System Design Techniques & Administrative Issues & $\begin{array}{l}\text { Evaluation Objectives } \\
\end{array}$ \\
\hline & System Acquisition & Financial Control Over IT & Evaluation Methods \& Techniques \\
\hline & & Security and backup recovery & $\begin{array}{l}\text { Communicating Results of } \\
\text { Evaluations }\end{array}$ \\
\hline & & Operational Issues & Following Up \\
\hline & & \multirow{2}{*}{$\begin{array}{l}\text { Management of System Acquisition, } \\
\text { Development, and Implementation }\end{array}$} & Specific Types of Evaluations \\
\hline & & & CAATS \\
\hline & & $\begin{array}{l}\text { Management of System Maintenance and } \\
\text { Change }\end{array}$ & \\
\hline & & Management of End-User Computing & \\
\hline
\end{tabular}

Source: International Federation of Accountants, International Education Guideline No. 11 (1995, revised 1998))

(a) Abbreviated descriptions. See related Figure 2, Concluded for more complete definitions of the concepts.

Development Standards \& Practices For Business Systems

Role of information in organization design $\&$ behavior Data bases \& data base management systems; SDLC; economic, technical, operational, and behavioral risks; controls

System design techniques Data flow diagrams; entity-relationship model; decision tables/trees; prototyping; CASE tools; data base design.

System Acquisition Investigation/feasibility study; requirements analysis \& initial design; detailed design specification/documentation; hardware evaluation, etc.

Management Of IT Adoption, Implementation, And Use

Strategic considerations in IT development Planning of information systems based on business success factors/criteria; components of longrange plans; integration with business objectives \& success factors; participation in strategic planning.

Administrative issues Job functions; organization; reporting relationships of the IT department; approaches to staffing, personnel development \& performance evaluation.

Financial control over IT IT budgeting and cost control.

Security and backup recovery Access availability and continuity

Operational issues Developing operational priorities; management of computer operations.

Management of system acquisition, development, and implementation Development acquisition alternatives; standards and controls applicable to IS development projects.

Management of system maintenance $\&$ change Standards and controls applicable to IS maintenance activities.

Management of end-user computing Role of information centers.

Evaluation Of Computer-Based Business Systems

Legal, ethical, auditing, and IS control standards Legal \& ethical requirements; auditing standards relevant to IT; computer control guidelines \& standards.

Evaluation objectives Efficiency/effectiveness/economy of IT use; compliance with policies, statutes and regulations; evaluation of internal control in computer-based systems; fairness of financial statement representations and the accuracy \& completeness of accounting records.

Evaluation methods \& techniques Planning, scheduling \& staffing; obtaining an understanding of systems in business context; documenting systems \& elements of control structure; tests of features, controls, transactions \& balances; supervision, review \& quality assurance.

Communicating results of evaluations.. Types of reports \& levels of assurance; communication skills.

Following up Frequency, reporting, etc.

Specific types of evaluations System acquisition and development; system implementation; system maintenance and program changes; IT asset safeguarding; data integrity, privacy \& security; continuity of processing/disaster recovery planning; system processing operations/activities; application processing.

CAATs Approaches (auditing around, through, with the computer); professional standards; feasibility considerations; categories of CAATs; definition and design; execution and control. 


\section{AHP INSTRUMENTS}

Guideline No. 11 includes eight competencies related to IT concepts for business systems, six related to internal control in computer-based business systems, and 18 related to the roles of the professional accountant in information systems. Because we believe that these competencies are appropriately evaluated by two distinct subject pools, we conducted two separate studies, referred to hereafter as Study 1 and Study 2.

In Study 1, participants were accounting educators with responsibilities for teaching AIS courses. Our objective was to assess the relative importance of two Guideline No. 11 categories: (1) IT concepts for business systems and (2) internal control in computer-based business systems. In Study 2, the goal was to assess the relative importance of the competencies related to the roles of the professional accountant in information systems. For Study 2, we sent the instrument to a small number of AIS faculty that we identified as leaders in AIS accounting education based upon professional stature.

\section{RESULTS}

\section{Study 1: IT Concepts for Business Systems and Internal Control in Computer-Based Business Systems}

Study 1 surveys were distributed in two ways. First, 80 were handed out at the Fourth Annual AIS Teaching Symposium in 2001. Second, an additional 45 were mailed directly to a sample of individuals attending the Accounting Information Systems Educator Conference in 2000. Return envelopes were distributed with the instruments to facilitate the return of the documents. Useable responses were received from 31 participants, which represent a 25\% response rate. Relevant sample demographics are as follows: 18 male and 13 female; 24 had professional certification (e.g., CPA); 27 held the rank of assistant, associate, or full professor; mean teaching experience was 13.4 years; and mean AIS teaching experience was 8.8 years.

The subjects came from a wide range of institutions, ranging from 15 to 400 undergraduate degrees granted annually. Additional institutional information is provided in Table 1.

Table 1

Participants' Institutional Demographics (a)

\begin{tabular}{|c|c|c|c|c|}
\hline Item & Minimum & Maximum & Mean & Median \\
\hline Undergrad accounting graduates per year & 15 & 400 & 127 & 105 \\
\hline Masters accounting graduates per year & 5 & 225 & 55 & 35 \\
\hline Accounting Faculty & 3 & 40 & 16 & 13 \\
\hline AIS Faculty & 0 & 5 & 2 & 2 \\
\hline Undergrad AIS courses offered per year & 0 & 10 & 1.6 & 1 \\
\hline Graduate AIS courses offered per year (b) & 0 & 7 & 1.9 & 2 \\
\hline Required AIS undergrad courses & 0 & 6 & 1.2 & 1 \\
\hline Required AIS graduate courses (b) & 0 & 7 & 1 & 0 \\
\hline
\end{tabular}

(a) There is a possibility of duplication in the institutional records, because the institution name was not obtained from the participants. This should not affect the range, but may impact the mean and have a minor impact on the median.

(b) For subjects reporting masters graduates

\section{AHP Weights of Relative Importance}

Table 2 presents the mean AHP weights (and ranks) for the 31 participants. Recall that the AHP weights represent the relative importance of factors. With respect to the eight IT concepts, the most important factor is data organization and access methods $(19.3 \%)$, followed by management use of information $(17.5 \%)$ and transaction processing (16.9\%). The least important concepts related to hardware (4.3\%) and system software $(7.3 \%)$. 
Table 2

Relative Importance of IT Competencies Related to IT Concepts for Business Systems and Internal Control in Computer-Based Business Systems (Study 1)

\begin{tabular}{lcc}
\hline Category (a) & $\begin{array}{c}\text { Mean AHP Weight } \\
(\mathbf{n = 3 1})(\mathbf{b})\end{array}$ & Rank \\
\hline IT Concepts For Business Systems & 0.134 & 4 \\
General systems concepts & 0.175 & 2 \\
Management use of information & 0.043 & 8 \\
Hardware & 0.073 & 7 \\
System software & 0.103 & 6 \\
Application software & 0.193 & 1 \\
Data organization and access methods & 0.169 & 3 \\
Transaction processing & $\underline{0.110}$ & 5 \\
Networks and electronic data transfer & $\underline{1.000}$ & 3 \\
& & 6 \\
Internal Control In Computer-Based Business Systems & 0.182 & 4 \\
Control objectives & 0.099 & 1 \\
Control framework & 0.174 & 2 \\
Control environment & 0.229 & 5 \\
Control activities & 0.200 & \\
Monitoring of control compliance & $\underline{0.116}$ & \\
& $\underline{1.000}$ & \\
\hline
\end{tabular}

(a) See Figure 1 for descriptions of each competency.

(b) Mean Inconsistency Ratio for $\mathrm{n}=31$ is 0.076 .

Table 2 also presents the relative importance of six internal control competencies. The order of importance is as follows: understanding risk assessment (22.9\%), control activities (20.0\%), control objectives (18.2\%), the control environment (17.4\%), monitoring of control compliance (11.6\%), and control framework (9.9\%).

Accounting educators may use these results in one of several ways The IT competencies in Guideline No. 11 were developed by accounting professionals as a list of competencies for entry-level accounting professionals. The results in Table 2 reflect the average consensus of how accounting educators assess the relative importance of the competencies cited by accounting professionals. Therefore, accounting educators can use this knowledge in assessing accounting curricula, which can provide valuable information, especially in programs and institutions where AIS resources are limited. In an ideal world, every institution could offer multiple courses in AIS, and/or redesign existing courses to include all of the competencies. Such actions would take significant commitments from non-AIS faculty in addition to institutional monetary support. By using a prioritization of the concepts, institutions may be able to compare their coverage of IT concepts to how important those concepts are to a sample of AIS educators. One may also be able to evaluate the resources required to adequately expand coverage to other significant topics.

The results also can be a useful benchmark for accounting professionals to learn how accounting educators view the relative importance of the IT competencies. It would be desirable that consensus among educators and practitioners exist if students are to be successful in the job market. However, until that consensus exists, practitioners may use the relative importance of the concepts to focus on post-employment training, based on realistic expectations of employee competencies, and yielding an improved satisfaction level in the employee-employer relationship.

\section{Study 2: Roles of the Professional Accountant}

The purpose of Study 2 was to have expert AIS educators assess the relative importance of the factors related to the roles of the professional accountant. Study 2 was distributed to 19 individuals that the authors non-randomly identified as leading AIS educators, based on professional reputations of the individuals (leadership positions in academic organizations, publications, and other information). Five usable instruments were returned (26.3\% response rate). The five respondents averaged nine years experience teaching AIS, and over thirteen years of total teaching experience. Because the sample size is small, we present the data for all five participants in Table 3, which is a 
common presentation in small-sample AHP studies wherein researchers are interested in analyzing the specific attributes of each subject's decision model. ${ }^{3}$

Table 3

Relative Importance of Roles of Professional Accountant in Information Systems Identified in IFAC Guideline No. 11 (Study 2)

CATEGORIES (a)

Develop standards \& practices for business systems

Management of IT adoption, implementation, \& use

Evaluation of computer-based business systems

\section{ROLES}

Development Standards \& Practices for Business Systems

Role of information in organization design \& behavior

System design techniques

System acquisition

Subtotal

Management of IT Adoption, Implementation, and Use

Strategic consideration in IT development

Administrative issues

Financial control over IT

Security and backup recovery

Operational issues

Management of system acquisition, development, \& implementation

Management of system maintenance \& change

Management of end-user computing

Subtotal

\section{Evaluation of Computer-Based Business Systems}

Legal, ethical, auditing, \& IS control standards

Evaluation objectives

Evaluation methods \& techniques

Communicating results of evaluations

Following up

Specific types of evaluations

CAATs

Subtotal

Total*

* Some totals do not sum to 1.000 because of rounding.

(a) See Figure 2 for a description of each competency.

\begin{tabular}{|c|c|c|c|c|c|c|}
\hline \multicolumn{7}{|c|}{ AHP Weight } \\
\hline \multicolumn{6}{|c|}{ Participant } & \multirow[b]{2}{*}{ Rank } \\
\hline 1 & 2 & 3 & 4 & 5 & Mean & \\
\hline 0.258 & 0.200 & 0.667 & 0.293 & 0.211 & 0.326 & 2 \\
\hline 0.637 & 0.200 & 0.167 & 0.066 & 0.109 & 0.236 & 3 \\
\hline$\underline{0.105}$ & $\underline{0.600}$ & $\underline{0.166}$ & $\underline{0.641}$ & $\underline{0.680}$ & $\underline{0.438}$ & 1 \\
\hline$\underline{\underline{1.000}}$ & $\underline{\underline{1.000}}$ & $\underline{\underline{1.000}}$ & $\underline{\underline{1.000}}$ & $\underline{\underline{1.000}}$ & $\underline{\underline{1.000}}$ & \\
\hline 0.083 & 0.070 & 0.049 & 0.111 & 0.009 & 0.064 & 7 \\
\hline 0.028 & 0.028 & 0.284 & 0.027 & 0.065 & 0.086 & 4 \\
\hline$\underline{0.083}$ & $\underline{0.011}$ & $\underline{0.102}$ & $\underline{0.038}$ & $\underline{0.024}$ & $\underline{0.052}$ & 9 \\
\hline$\overline{0.194}$ & $\overline{0.109}$ & $\underline{0.435}$ & $\overline{0.176}$ & $\overline{0.098}$ & $\underline{\underline{0.202}}$ & \\
\hline 0.128 & 0.019 & 0.053 & 0.004 & 0.005 & 0.042 & $12 / 13$ \\
\hline 0.031 & 0.009 & 0.014 & 0.020 & 0.005 & 0.016 & 17 \\
\hline 0.137 & 0.008 & 0.071 & 0.004 & 0.033 & 0.051 & 10 \\
\hline 0.072 & 0.066 & 0.063 & 0.014 & 0.018 & 0.047 & 11 \\
\hline 0.033 & 0.009 & 0.015 & 0.025 & 0.007 & 0.018 & 16 \\
\hline 0.205 & 0.070 & 0.042 & 0.012 & 0.013 & 0.068 & 6 \\
\hline 0.062 & 0.045 & 0.027 & 0.021 & 0.020 & 0.035 & 14 \\
\hline 0.020 & 0.008 & 0.012 & 0.006 & 0.020 & $\underline{0.013}$ & 18 \\
\hline$\overline{0.688}$ & $\overline{0.234}$ & $\overline{0.297}$ & $\overline{0.102}$ & $\overline{0.116}$ & $\overline{0.287}$ & \\
\hline 0.034 & 0.120 & 0.034 & 0.242 & 0.043 & 0.095 & 3 \\
\hline 0.027 & 0.052 & 0.028 & 0.177 & 0.103 & 0.077 & 5 \\
\hline 0.027 & 0.209 & 0.025 & 0.131 & 0.175 & 0.113 & 1 \\
\hline 0.007 & 0.033 & 0.071 & 0.030 & 0.069 & 0.042 & $12 / 13$ \\
\hline 0.006 & 0.023 & 0.013 & 0.038 & 0.043 & 0.025 & 15 \\
\hline 0.010 & 0.168 & 0.026 & 0.076 & 0.208 & 0.098 & 2 \\
\hline$\underline{0.007}$ & $\underline{0.052}$ & $\underline{0.071}$ & $\underline{0.024}$ & $\underline{0.140}$ & $\underline{0.059}$ & 8 \\
\hline$\overline{0.118}$ & 0.657 & $\overline{0.268}$ & $\overline{0.718}$ & $\overline{0.781}$ & $\overline{0.508}$ & \\
\hline$\overline{1.000}$ & 1.000 & $\overline{1.000}$ & $\overline{0.996}$ & $\overline{0.995}$ & 0.998 & \\
\hline
\end{tabular}

1.000

The Table 3 data are interesting because observation suggests that the relative weights assigned by three participants $(2,4$, and 5) are very different than those assigned by participants 1 and 3 . Participants 2,4 , and 5 placed considerable weight on one of the three roles, evaluation of computer-based business systems (relative weights of $0.657,0.718$, and 0.781 , respectively). However, participants 1 and 2 placed weights of 0.118 and 0.268 on this category. For Participant 1, management of IT adoption was the most important category (weight $=0.688$ ), and Participant 3 weighted the development of standards and practices for business systems category as most important (weight $=0.435$ ). Although the sample sizes are small, these results reflect considerable difference among the participants as to the relative importance of the IT competencies related to the roles adopted by professional accountants. This small group of influential AIS educators appears to disagree on the relative importance that should be placed on IT competencies related to the roles of professional accountants in accounting (business) curricula. No consensus exists among all of the respondents, relating to the roles are most important.

The diversity of responses is consistent with previous studies. For example, Groomer \& Murthy (1996) suggested that the varied backgrounds of instructors may affect course content. Additionally, it is reasonable to 
expect a faculty member's level assessment of importance for a specific factor to be driven by personal knowledge of the job market in which his or her institution places students.

Without knowing the source, it is still important that we recognize and acknowledge the diversity that exists among leading AIS educators. These individuals will likely be dominant in curriculum development for their institutions and influence the direction of this important and growing segment of accounting education.

\section{DISCUSSION}

Developed and endorsed by accounting professionals, IFAC International Education Guideline No. 11 established IT competencies that should be possessed by entry-level accounting professionals. In this study, we report how AIS accounting educators rated the relative importance of the Guideline No. 11 IT competencies. Because of the wide divergence of in AIS texts and accounting curricula regarding how the Guideline No. 11 IT competencies should be included, we believe that the results assessing relative importance from a cross-sectional sample will prove interesting to AIS educators In Study 1, we found that AIS educators rank data organization and access methods, and management use of information as the most important items within the category of IT concepts for business systems. The lowest ranked items in that category are system software and hardware. Within the category of internal control in computer based business systems, AIS educators ranked risk assessment and control activities highest; the lowest ranked items in that category were the control framework and monitoring of control compliance. The results can be used by accounting professionals to help understand how accounting educators rate the relative importance of the IT competencies and by accounting educators when assessing accounting curriculum.

Limitations of the research are those commonly associated with survey research. We are unable to determine what background factors or beliefs of the participants are associated with their AHP responses. As in all survey research, there may be issues related to the participants' interpretations of the instrument. Additionally, because of our research design choices, including instrument length issues, participants in Study 1 did not rate the Guideline No. 11 related to roles of the professional accountant. Future research opportunities include replicating the survey with accounting professionals. Although the IFAC standards were developed by professionals, Guideline No. 11 provides no prioritization of importance to educators for curricular design. Therefore, information about the relative importance to accounting professionals would be useful. Reconciliation of the differences in academic and professional assessments would be an ultimate goal, helping each understand and recognize the attitudes and expectations of the other. Also, future survey research could focus on the extent of course coverage of the Guideline No. 11 factors rather than the relative importance of the factors.

\section{REFERENCES}

1. AICPA (American Institute of Public Accountants), Information technology competencies in the accounting profession: AICPA implementation strategies for IFAC International Education Guideline No. 11, AICPA, New York, 1996.

2. Apostolou, B.A. and Hassell, J.M., "An overview of the analytic hierarchy process and its use in accounting research", Journal of Accounting Literature, Vol. 12, pp. 1-28, 1993.

3. Arrington, C.E., Hillson, W. and Jensen, R.E., "An application of the analytical hierarchy process to model expert judgments on analytical review procedures", Journal of Accounting Research, Vol. 22, No. 1, pp. 298312, 1984.

4. $\quad$ Bain, C.E., Blankley, A.I., and Smith, L.M., "An examination of Topical Coverage for the first accounting information systems course", Journal of Information Systems, Vol. 16, No. 2, pp. 143-164, 2002.

5. Borthick, A.F., "Helping accountants learn to get the information managers want: The role of the accounting information systems course", Journal of Information Systems, Vol. 10, No. 2, pp. 75-85, 1996.

6. Callaghan, J., Peacock, E., and Savage, A., "Assessment of an accounting information systems curriculum: An Analysis of the International Federation of Accountants' International Education Guideline No. 11," Review of Accounting Information Systems, Vol. 4, No. 1, pp. 1-12, 2000.

7. Callaghan, J., Peacock, E., and Savage, A., "Feedback on Developing an AIS Curriculum", The Review of Business Information Systems, Vol. 5, No. 4, pp. 51-60, 2001. 
8. Davis, J.R. and Leitch, R.A., "Accounting information systems courses and curricula: New perspectives", Journal of Information Systems, Vol. 2, No. 2, pp. 153-166, 1988.

9. Groomer, S.M., and Murthy, U.S., "An empirical analysis of the accounting information systems course", Journal of Information Systems, Vol. 10, No. 2, pp. 103-127, 1996.

10. Heagy, C.D., and McMickle, P.L., "An empirical investigation of the accounting systems course: Academic practice versus practitioner needs", Issues in Accounting Education, Vol. 3, No. 1, pp. 96-107, 1988.

11. IFAC (International Federation of Accountants), Information technology in the accounting curriculum. International Education Guideline No. 11, IFAC, New York, NY, 1995 revised 1998.

12. Macur, K.M., "The curricular content of accounting information systems", The Review of Accounting Information Systems, Vol. 2, No. 3, pp. 11-19, 1998.

13. Saaty, T. L., Decision Making for Leaders, RWS Publications, Pittsburgh, PA, 1986.

14. Saaty, T. L., The Analytic Hierarchy Process, RWS Publications, Pittsburgh, PA, 1988.

15. Saaty, T. L., "The analytic hierarchy process: Some observations on the paper by Apostolou and Hassell", Journal of Accounting Literature, Vol. 13, pp. 212-219, 1994.

16. Smith, L.M., and Bain, C.E., "The scope of the accounting information systems course: Based on textbook coverage and a faculty survey," Accounting Educators' Journal, Vol. 5, No. 2, pp. 1-11, 1993.

17. Walton, K.S., "Current approaches to structuring the information systems curriculum for accounting majors", Accounting Educators' Journal, Vol. 9, No. 2, pp. 69-88, 1997.

\section{ENDNOTES}

\footnotetext{
${ }^{1}$ MIS courses are generally taught outside of accounting departments and frequently outside of business schools.

${ }^{2}$ The individuals selected (nonrandomly) for the Study 2 were known to the researchers as leaders in AIS education through their participation in academic organizations, publications on AIS topics, and/or interest in AIS education issues.

${ }^{3}$ By conventional standards, Study 2 appears to be too small to draw inferences. However, the AHP was designed to be used to document the decision models of expert decision makers (Saaty 1988) and to help non-experts model their own decisions like experts. Accordingly, each AHP model is unique to the individual. In larger samples, AHP researchers have adopted the convention of aggregating across subjects and using conventional parametric and nonparametric tests (as we do in Study 1). However, for smaller studies with expert decision makers, AHP researchers typically provide the decision models of all participants so that readers can evaluate the individual decision models for the one that makes sense to their particular situation or environment (e.g., see Arrington, Hillison, \& Jensen (1984), which was the first major AHP study in the accounting literature).
} 